\title{
Effect of Applied Load on Dry Sliding Wear Property of Aged TiNiCu Alloy
}

\author{
Narendranath.S1, S. Basavarajappa ${ }^{2}$, K.V. $\operatorname{Arun}^{3}$, S. Manjunath Yadav,** \\ ${ }^{1}$ Department of Mechanical Engineering,National Institute of Technology, Srinivasanagar, \\ Surathkal, Karnataka, India \\ ${ }^{2}$ Department of studies in Mechanical Engineering, University B D T College of \\ Engineering, Davanagere-577 004 India \\ ${ }^{3}$ Department of studies in I \& P Engineering, University B D T College of Engineering, \\ Davanagere-577 004 India \\ * Corresponding Author: manjunathyadavs@ gmail.com
}

\begin{abstract}
Titanium Nickel Shape Memory Alloy (SMA) has demonstrated its great potential for a large variety of applications. This alloy is being actively applied to the development of new energy conversion systems, to the design for new robots and smart material systems and to the development of medical implants and instruments. In addition to its shape memory effect, it is necessary to understand the wear behavior of Titanium Nickel SMA Alloys. Hence in this article the wear behaviour of a TiNiCu+ alloy aged at different temperature have been studied against EN 31 steel (62HRc). The results indicate that the ageing temperature greatly affect the dry sliding wear behavior of TiNiCu alloy.
\end{abstract}

Keywords: Shape memory alloy; Ageing temperature; Weight loss; Hardness.

\section{INTRODUCTION}

In the past decades, shape memory alloys are known to exhibit recoverable strains of the order of 10 percent. Out of all these shape memory alloys, near equiatomic TiNi stands as a well-known shape memory alloy [1-3]. This is attributed to its shape memory effect. The shape memory effect results from thermoelastic martensitic transformation. On cooling the parent B2 phase having an ordered $\mathrm{BCC}(\mathrm{CsCl})$ structure transforms to a martensite phase possessing a monoclinic structure of B19' type [4]. Martensitic transformation comprises of two types namely 
thermoelastic and reversible transformations. In the former transformation, martensite starts (Ms) to form as soon as Ms is reached and is completed below martensitic finish (Mf) temperature. In the latter transformation, B2 to B19' can be brought about by an external stress at a temperature above Ms. On removal of the stress, B2 phase can be recovered. As a result of the reversibility of the martensitic transformation, near equiatomic TiNi alloys exhibit a unique mechanical behavior termed as pseudoelasticity. With the pseudoelasticity, recoverable strain reaches up to the order of 8 percent or even higher [5]. The pseudoelasticity is believed to depend on many factors such as crystal structures of the martensite and parent phase, microstructure and thermal history [3].

In recent years, TiNi alloy has been found to possess excellent resistance to erosion, abrasive wear and especially to cavitation [4-9]. It showed superior performance compared with many conventional engineering materials and commercial wear resistant materials. The high wear resistance of TiNi alloy in addition to its shape memory effect makes it more attractive particularly to tribologists and material scientists. Compared to conventional wear resistant materials, hardness is not the important parameter that dominates the wear resistance of TiNi alloy [7, 8]. It was suggested that the high wear resistance of TiNi alloy is mainly owing to its pseudoelasticity [6-9]. Strain hardening was also found to contribute to the wear resistance of TiNi alloy [10]. Liang et al [6] investigated the performance of TiNi alloys during sliding wear, impact, abrasion and sand blasting erosion. They reported that TiNi alloys having higher pseudoelasticity exhibited better wear resistance than those deprived of it. Shida et al [7] studied the erosion behavior of TiNi alloys and observed that the erosion resistance of TiNi alloys was strongly dependent on chemical composition and microstructure rather than on the hardness. They indicated that the excellent erosion resistance of TiNi alloys might be related to pseudoelasticity associated with the thermoelastic martensitic transformation.

In the present study, emphasis is laid on the ageing effect on wear behavior of $\mathrm{Ti}_{50} \mathrm{Ni}_{45} \mathrm{Cu}_{5}$ alloy, understanding of the morphology of the wear surface and consequently, the wear characteristics of the $\mathrm{Ti}_{50} \mathrm{Ni}_{45} \mathrm{Cu}_{5}$ alloy.

\section{EXPERIMENTAL}

$\mathrm{Ti}_{50} \mathrm{Ni}_{45} \mathrm{Cu}_{5}$ alloy was prepared by Vacuum Induction Melting (VIM). The prepared $\mathrm{Ti}_{50} \mathrm{Ni}_{45} \mathrm{Cu}_{5}$ alloys were followed by homogenization treatment at $900^{\circ} \mathrm{C}$ for $5 \mathrm{hr}$. The obtained TiNi alloys were annealed at $750^{\circ} \mathrm{C}$ in argon atmosphere for $45 \mathrm{~min}$, followed by furnace cooling; the annealed $\mathrm{Ti}_{50} \mathrm{Ni}_{45} \mathrm{Cu}_{5}$ alloy was divided into four groups, and aged at $350^{\circ} \mathrm{C}, 400^{\circ} \mathrm{C}, 450^{\circ} \mathrm{C}$ and $500^{\circ} \mathrm{C}$ in argon atmosphere for 45 min respectively followed by furnace cooling.

Wear tests were conducted using pin on disk wear testing machine, the disc was made with EN 31 steel having hardness of $62 \mathrm{HRc}$. The wear tests were carried out on $\mathrm{Ti}_{50} \mathrm{Ni}_{45} \mathrm{Cu}_{5}$ alloy with specimen of $4 \mathrm{~mm}$ thickness and cross sectional area of $8 \times 8 \mathrm{~mm}^{2}$. The experiments were 
carried out under a constant speed of $1 \mathrm{~m} / \mathrm{s}$, constant Sliding distance of 360 meters and a track diameter of $80 \mathrm{~mm}$, with various loads of 10, 20, 30 and $40 \mathrm{~N}$. The responses studied were wear losses and frictional forces. All the tests were carried out at room temperature. The microstructure of the worn surface samples are studied with an aid of scanning electron microscopy (SEM, JEOL-5400). The hardness was measured using Rockwell hardness testing machine.

\section{RESULTS AND DISCUSSION}

The effect of hardness on ageing temperature is as shown in Fig.1. The hardness of $\mathrm{Ti}_{50} \mathrm{Ni}_{45} \mathrm{Cu}_{5}$ alloys decreases with increase in ageing temperature. Addition of $\mathrm{Cu}$ in TiNi alloy minimizes the formation of secondary metastable precipitate $\left(\mathrm{Ti}_{3} \mathrm{Ni}_{4}\right)$, which may be reason for the decrease in hardness. The hardness values were found to lie in the range 32HRc to 39HRc.

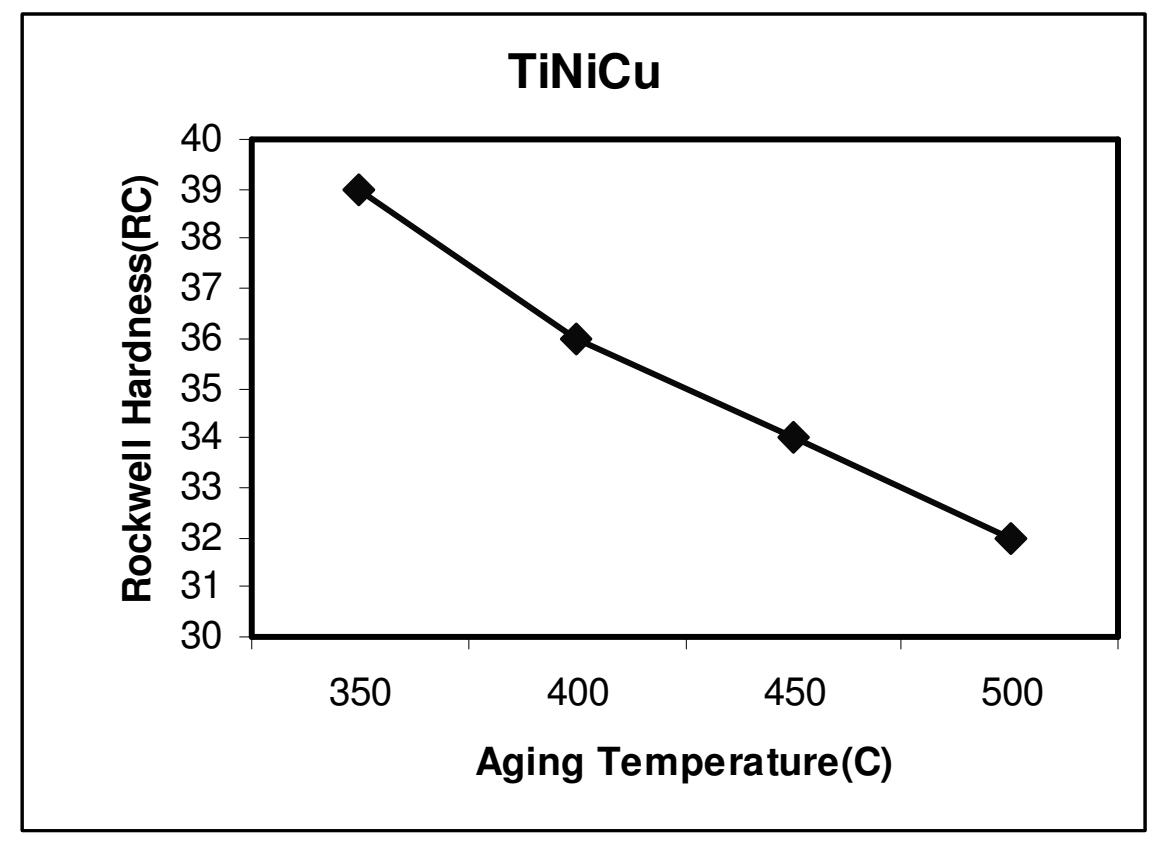

Fig. 1. Hardness of aged TiNi alloys plotted against ageing temperature.

Fig. 2 shows the effect of aging temperature for (a) Wear weight loss (b) Co-efficient of friction of aged $\mathrm{Ti}_{50} \mathrm{Ni}_{45} \mathrm{Cu}_{5}$ shape memory alloys against the applied load at a constant sliding distance 360 meters and a sliding speed of $1 \mathrm{~m} / \mathrm{s}$. The wear weight loss and co-efficient of friction of these alloys increases with the increase of normal load. 

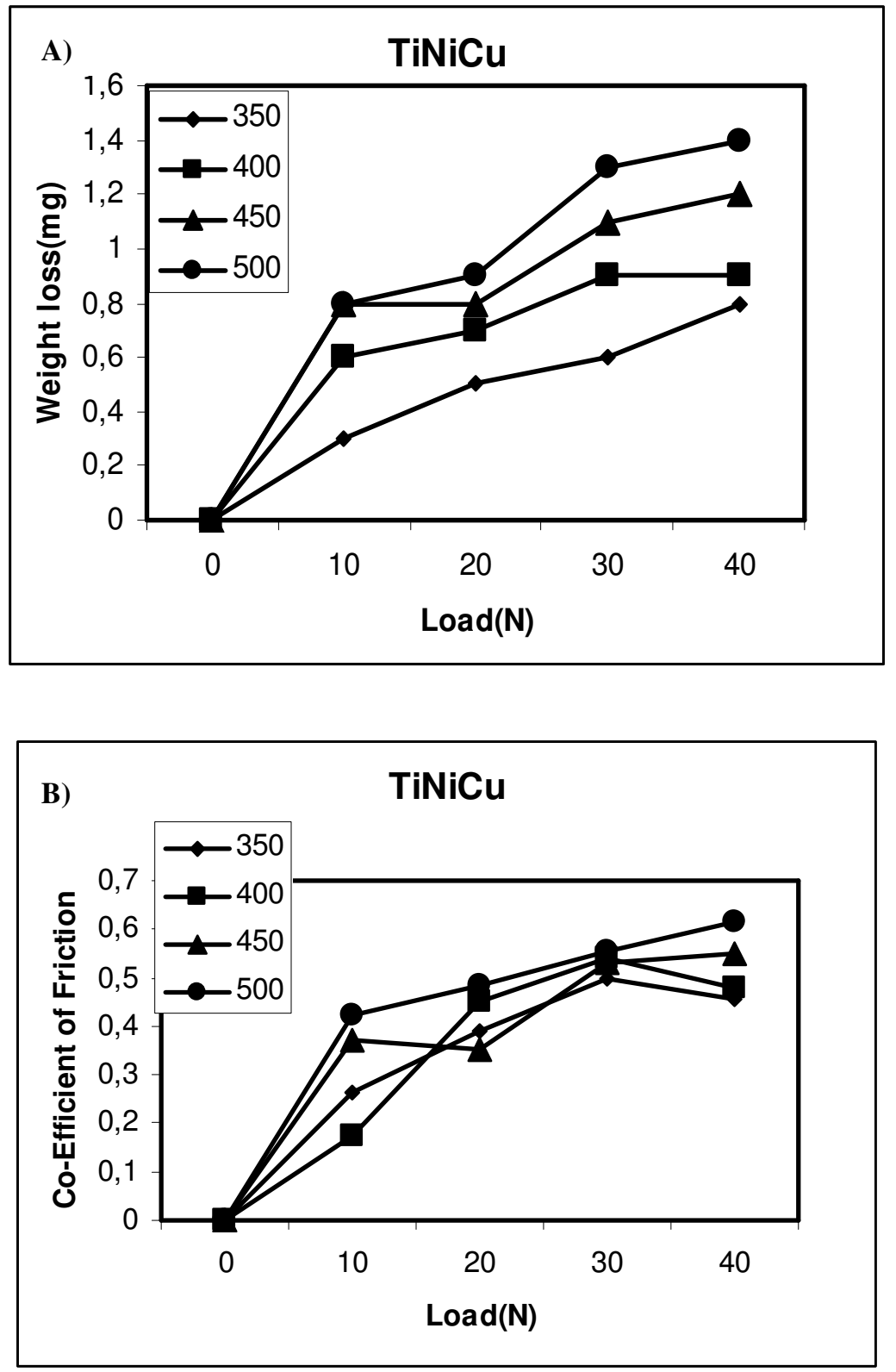

Fig. 2. Weight Loss and Coefficient of friction of aged $\mathrm{Ti}_{50} \mathrm{Ni}_{45} \mathrm{Cu}_{5}$ alloys plotted against the Load at sliding distance of $360 \mathrm{~m}$, sliding speed of $1 \mathrm{~m} / \mathrm{s}$ at different aged samples. (A) Wear weight loss (B) Co-efficient of friction.

It can be seen that wear resistance of the alloys decreases with the increase of ageing temperature (Fig. 2) .This is because as the ageing temperature increases the hardness decreases which in turn causes the increase of weight loss and co-efficient of friction [11-13]. 
Failure of a material during sliding depends on its properties, the applied load and the contact geometry. Since a material surface unavoidably consists of asperities, normal and tangential loads are transmitted through the interacting asperities when two surfaces come into contact. It has been demonstrated by experiments and the delamination theory that, during sliding wear process, the subsurface undergoes plastic deformation and maximum plastic strain occurs beneath the contact area. As the plastic strain accumulates and reaches the critical strain to fracture, crack nucleates \& then propagates, leading to eventual material removal from surface. In general, a homogeneous material having high yielding strength, high strain-hardening capacity and large facture strain may exhibit high wear resistance. These properties assist to reduce the plastic strain and provide a long lifetime before the accumulated plastic strain reaches the critical strain to fracture.

The weight loss and co-efficient of friction are found to be increasing with the increase of load. These experimental results obey Archard's law;

$$
R=K(P / H) \times
$$

Where $R, K, P, H$ and $v$ denote respectively, wear volume, wear coefficient, Load, hardness and velocity. Namely, the wear rate is proportional to $P$, inversely proportional to hardness.

Fig. 3 shows the worn surface morphologies taken at the central region at $20 \mathrm{~N}$ applied load for aged $\mathrm{Ti}_{50} \mathrm{Ni}_{45} \mathrm{Cu}_{5}$ alloy at different temperature. Usually, four main wear mechanisms adhesion, abrasion, surface fatigue and brinelling are observed during dry sliding wear tests of TiNi alloys. But, difference of hardness between $\mathrm{Ti}_{50} \mathrm{Ni}_{45} \mathrm{Cu}_{5}$ alloys (39 Rc) and EN 31 steel (62 Rc) ensures abrasive type of wear mechanism. The ploughing grooves (Fig. 3) illustrate the abrasive wear, which originates from the interaction, microcutting and plastic deformation. Due to repeated loading and unloading cycles, many surface or subsurface cracks form and eventually results in the breakup of the surface. At the same time, Fig. 3(a) shows the wavy tracks in outer surface. This feature is so called brinelling wear occurs from the plastic deformation of softer materials. It should be mentioned that phenomenon of brinelling wear will increase the friction co-efficient, but it has little contribution to weight loss.

The pearl like crests appearing in Fig. 3(c) should be ascribed to the accumulation of adhesive junction, abrasive deformation and wear chips and the mechanical locking of surface pits. These pearl like crests will increase the fluctuation of friction co-efficient during sliding wear process and rapidly increase the weight loss due to mechanical fracture. 

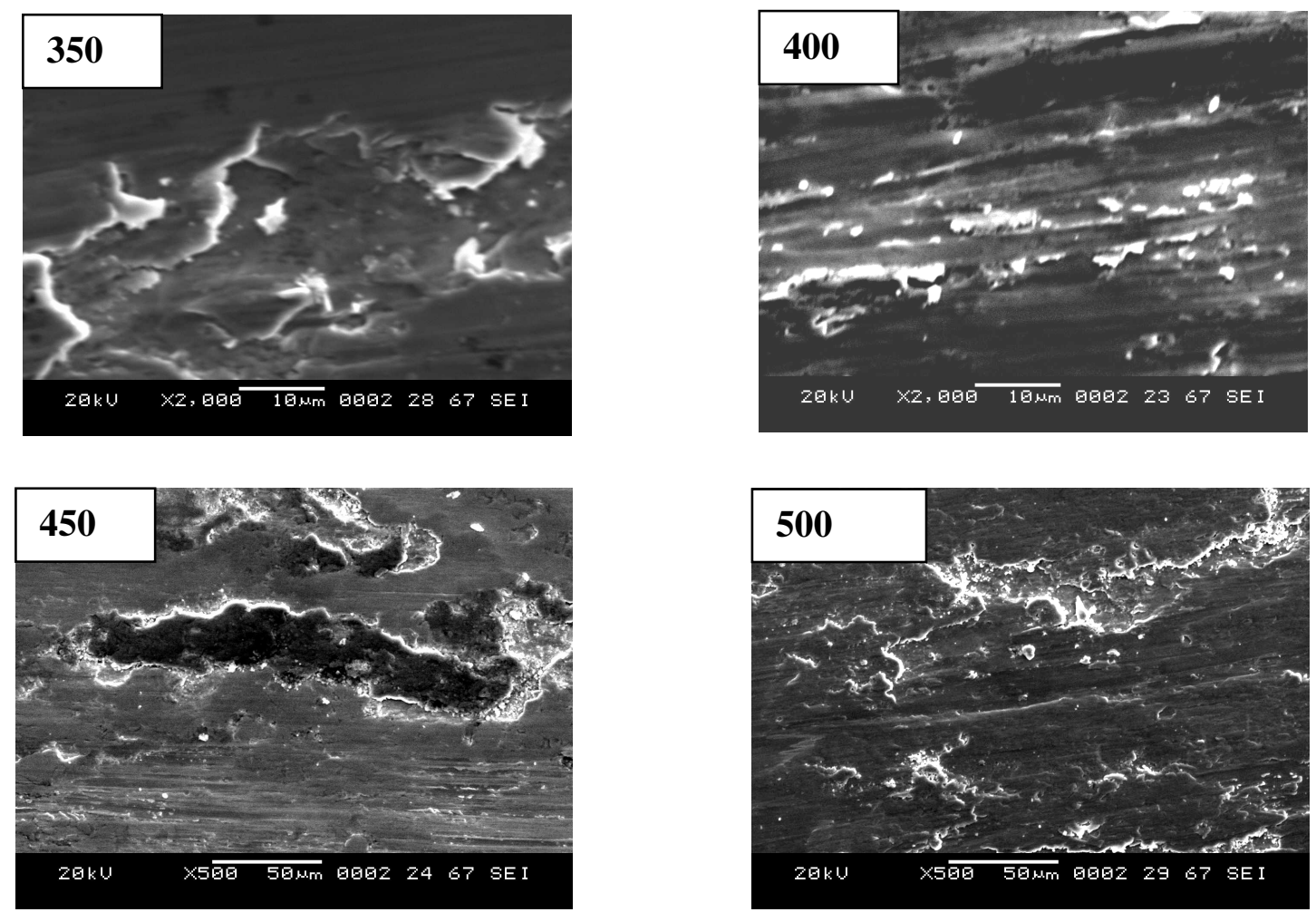

Fig. 3. SEM micrographs of worn surface of aged $\mathrm{Ti}_{50} \mathrm{Ni}_{45} \mathrm{Cu}_{5}$ alloy.

\section{CONCLUSIONS}

Based on the experimental analysis the following conclusions are derived.

- Weight loss increases with the increase of ageing temperature, this is due to decrease in hardness of the $\mathrm{Ti}_{50} \mathrm{Ni}_{45} \mathrm{Cu}_{5}$ alloys.

- Apart from metallurgical properties, applied load has considerable influence on wear characteristics, the weight loss and co-efficient of friction increases with increase in the normal load.

- Four main mechanisms, adhesion, abrasion, surface fatigue and brinelling are found to have important contributions to the wear characteristics of the aged $\mathrm{Ti}_{50} \mathrm{Ni}_{45} \mathrm{Cu}_{5}$ alloys. 


\section{REFERENCES}

1. Wayman, C.M., Editor, 1964, Introduction to the Crystallography of Martensite Transformations, MacMillan, New York.

2. Miyazaki, S., Otsuka, K., Suziki, Y., 1981, "Transformation pseudoelasticity and deformation behavior in a Ti-50.6at\%Ni alloy." Scripta Metallurgica, Vol.15, Issue 3, pp.287-292.

3. Tanaka, K., Kobayashi, S., Sato, Y., 1986, "Thermomechanics of transformation pseudoelasticity and shape memory effect in alloys.'Int. Journal of Plasticity, Vol.2, pp. 59-72.

4. Otsuka, K., Shimizu, K., 1977, "On the crystallographic reversibility of martensitic transformations.' ScriptaMetallurgica, Vol.11, Issue9, pp.757-760.

5. Duerig, T.W., Zadno, R., Editors, 1990, Engineering Aspects of Shape Memory Alloys, Butterworth-Heinemann, London.

6. Liang, Y. N., Li, S.Z., Jin, Y.B., Jin, N., Li, S., 1996, "Wear behavior of a TiNi alloy", Wear, Vol. 198, Issue 1-2, pp.236-241.

7. Shida, Y., Sugimoto, Y., 1991, "Water jet erosion behaviour of Ti-Ni binary alloys." Wear, Vol. 146, Issue 2, pp.219-228.

8. Richman, R.H., Rao, A.S., Hodgson, D.E., 1992, "Cavitation erosion of two NiTi alloys." Wear, Vol. 157, Issue 2, pp.401-407.

9. Li, D.Y., 1998, "A new type of wear-resistant material: pseudo-elastic TiNi alloy." Wear, Vol. 221, Issue 2, pp. 116-123.

10. Clayton,P.,1993, “Tribological behavior of a titanium-nickel alloy." Wear, Vol.162 -164, Part 1, pp. 202-210.

11. Vingsbo, O., 1979, Wear and Wear Mechanisms, In: Wear of Materials, ASME, pp. 620-635, New York.

12. Halling, J., Editor, 1976, Introduction to Tribology, Wykehan Publications Ltd., London.

13. Cowan, R.S., Winer, W.O., 1992, Friction, Lubrication and Wear Technology, In: ASM Hand Book, vol.18, pp.39-44, (Balu, P., Ed.), Materials Park, OH. 